\title{
NEW PROGRAMMING EDUCATION FOCUSING ON PROBLEM SOLVING SKILLS BY "POV-RAY"
}

\author{
Jumpei Gohara ${ }^{1}$, Yuki Watanabe ${ }^{1}$, Akifumi Sako ${ }^{1}$ and Mitsuaki Fujita ${ }^{2}$ \\ ${ }^{1}$ Tokyo University of Science, 1-3, Kagurazaka, Shinjuku-ku, Tokyo, 162-0825, Japan \\ ${ }^{2}$ Azabu High School, 2-3-29, Motoazabu, Minato-ku, Tokyo, 106-0046, Japan
}

\begin{abstract}
We developed a new curriculum of programming education for high school students by using "POV-Ray" software. This software is a ray tracing software which draws 3D images. The language of POV-Ray is similar to the C programming language. We think POV-Ray is more suitable for programming education than $\mathrm{C}$ language in that the result is outputted as a figure. Then, we designed and practiced nine lectures. At the beginning students could only make simple figures, e.g., spheres, boxes. However, they finally became able to make complicated images oceans, chess board, etc.
\end{abstract}

\section{KEYWORDS}

Programming Education, Problem-based Learning, Creativity Skills

\section{INTRODUCTION}

We developed a new curriculum of programming education for high school students by using "POV-Ray" software. Programming education is attracting attention in order to educate Assessment and Teaching of 21st Century Skills (ATC21s) in Japan (Ministry of Internal Affairs and Communications (2017)). ATC21s comprise abilities that have been identified as the requirements of success in 21 st century society and workplaces. In particular, problem-solving, cogent reasoning and critical thinking are considered important and strongly related to programming education. Therefore, a better programming education curriculum is required.

POV-Ray is a ray tracing software which draws 3D images from a text-based scene description. For example, this software can create 3D images by combining move, rotate and scale operations with basic objects, e.g., boxes, spheres. The scene description language of POV-Ray is similar to the $\mathrm{C}$ programming language. Students are easy to understand a result of POV-Ray program, because POV-Ray can easily generate images and visualize the source code. We think that POV-Ray is better than the $\mathrm{C}$ in classroom activities.

\section{CURRICULUM DESIGN}

We adopted John Keller's ARCS Model (Keller (1983)) in instructional design. The ARCS Model is based on the motivational design theories and consists of four categories, Attention, Relevance, Confidence and Satisfaction (ARCS). For example, The Attention can be gained in perceptual arousal. We think that the experience of creating 3D images with simple programming stimulates the interests of students. For the Relevance we use examples that students know well. We think that students can find meaning in the program by making familiar things in their life. They observe what they want to create, and think about ways to realize by program. This leads to the Confidence of them when they were able to create 3D images as they imagined. Since POV-Ray can visualize the program as a 3D image, teachers can easily give feedback depending on their imagination for the Confidence. They will get a sense of Satisfaction by becoming able to make more complicated things with new knowledge. 
Our curriculum has focused on high school second graders (eleventh-grade students) because having the mathematical knowledge (e.g., knowledge of trigonometric functions) might be necessary for them. The curriculum consists of nine lessons. The lesson starts from a simple program that creates a sphere as a basic object (Figure 1), they will become able to create more objects with each attendance to the lessons. Finally, they make their own original 3D image. Also, we use "include files" in the lessons. A include file is specific file that increase work efficiency by creating frequently used functions in separate files. Even if the program of object is complexly, we can teach it according to the student's level by preparing the appropriate include files. Learner analysis is particularly important to prepare include files at the appropriate level.

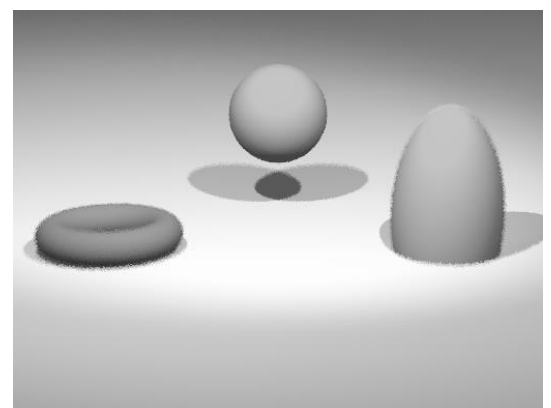

Figure 1. Example of Students' Work in the First Lesson

\section{CONCLUSION}

In our practice the following results were obtained. Creating a 3D image from a program was a new experience for the students. Many of them were interested in this lesson and actively working on it. Finally, they have created 3D images of their interest such as an airplane, oceans, chess, etc (Figure 2). by programming. This seems to train problem-solving ability in the sense that students realized what they imagined by the programming. In this presentation we will discuss more details such as the content of the curriculum and the work of the students. Also, we will introduce 3D images actually created by students.

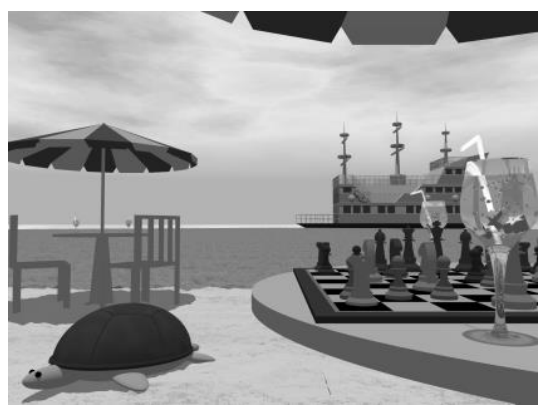

Figure 2. Example of Students' Work in the Final Lesson

\section{REFERENCES}

Keller, J.M, 1983. Motivational design of instruction. In C. M. Reigeluth (Ed.), Instructional design theories and models: An overview of their current status. Hillsdale, NJ: Lawrence Erlbaum Associates.

Ministry of Internal Affairs and Communications, 2017. Study on the way to educate programming human resources. Japan. 